\title{
The Reign of Leadership \& Power in Just Organizations
}

\author{
Silva Karkoulian \\ Lebanese American University \\ E-Mail: skarkoul@lau.edu.lb
}

\begin{abstract}
This study aims to illuminate the solid correlation between leadership that is employed in a Lebanese industry, organizational justice (OJ), and power that acts as the mediator between the two variables. This study intends to empirically validate that leadership style affects OJ, provided that power acts as the liaison. The sample consisted of 400 individuals working in small- to medium-sized multinational and Lebanese firms, specializing in the telecommunication and electronics retail sector, located throughout Lebanon. Path and regression analyses were employed to analyze the data and reach conclusions. The findings show that successfully implemented leadership paves the way for OJ through the basis of power exerted in an organization.

These findings are of additional value to the wide-ranging studies of human resources in business organizations and widen the scope of just treatment and fairness perceptions in the workplace. Promoting justice in organizations will lay the groundwork for a successful organization that can excel and become a pioneer in its field. Therefore, successful leaders should strive to promote perceptions of fairness in their organization in order to construct an ethical and a just workplace for their subordinates.
\end{abstract}

Keywords: Organizational Justice, Leadership, Power, Managers, Lebanon

\section{INTRODUCTION}

For the past few decades, theorists and scholars have been engaged in in-depth studies on organizational behaviors and attitudes and their implications and have conveyed wide-ranging hypotheses to validate their findings. One of such thoughtprovoking studies presented an interesting medley of variables consisting of leadership, organizational justice (OJ) (Tatum et al., 2003), and power. The upsurge of this deliberation is a result of the vast revolution that the business world is witnessing 
today. Leaders in organizations are aware of the implications of $\mathrm{OJ}$ and its significance in the workforce (Moon et al., 2008). Employees tend to value fairness within their organization and alter their behaviors accordingly. On the other hand, leaders may exercise power in order to achieve organizational goals. Since employees constitute the firm's most valuable assets, their leaders' behavior affects organizational outcomes (Choudhry et al., 2011). Thus, the dominating leadership style in an organization can be counted as a major asset if it contributes to the overall organizational efficiency, productivity, and growth; this gives rise to the importance of studying the effect of different leadership styles on organizational justice in particular, since a fair and just organizational environment is a key for maintaining a satisfied and motivated workforce.

It is without a doubt then, that the three concepts - leadership style, organizational justice, and power - are interrelated and affect one another in various ways and dimensions. The importance of these three main concepts stems from their major contribution to not only the effectiveness and efficiency of any business organization, but also to the sustainability of a fair environment for the employees which in turn is considered very crucial for long-term growth and success. According to Dijke et al. (2012), implementing a leadership style that provokes fairness and justice in an organization will ultimately encourage cooperative employee behaviors such as organization citizenship behavior.

Different works of research have been conducted to examine organizational behavior and leadership style conceptions in reference to turnover rates, commitment, and job satisfaction (Anderson \& Ackerman-Anderson, 2011; Long \& Thean, 2011). Contemporary studies associate OJ and decision making to leadership styles (Eberlin, 2005). However, to the knowledge of the researcher, no empirical study has probed the relationship between organizational justice in its three main facets (procedural, distributive, and interactional) and leadership styles (transformational, laissez-faire, and transactional), while treating power as a vital mediator between the two. Thus, the researcher proposes that the leadership style may affect to a certain degree the type of justice present in an organization mediated by the kind of power he/she exercises. In this paper, the researcher strives to determine what leadership style will help create a fair and just environment with the maximized level of perceived organizational justice and how exerting the right level and type of power can act as a successful mediator to facilitate the link between the leadership style and level of organizational justice.

The following section discusses the three commonly known types of leadership styles: transactional, transformational, and laissez-faire leadership. The remaining 
sections of this paper focus on defining the other two variables under study, power and organizational justice, before moving on to determining the link between the three.

\section{LEADERSHIP STYLES, POWER \& ORGANIZATIONAL JUSTICE (OJ)}

\section{Leadership}

Many scholars are in harmony when it comes to the fact that each situation requires a certain leadership style. For instance, where the classical thinking of leadership styles revolves around the behavior and decision-making style of the leader, a more modern and commonly known leadership style, transactional leadership, focuses on careful organization of the subordinates' tasks, thus leading to maximized job efficiency; on the other hand, transformational leadership is all about the leader's charisma and the way he/she inspires, stimulates, and encourages his/her followers, leading to increased levels of creativity and organizational growth and productivity (Samad, 2012). Novel paradigms comprise transactional, laissez-faire, and transformational leaders (Bass, 1985; Avolio et al., 1999).

The importance of studying leadership styles and the way leadership is implemented was also shown in Yuan and Lee's study (2011), in which the successful application of leadership greatly affected the level of efficiency in an organization and the extent to which it reaches its objectives and goals, and what mainly contributed to leadership effectiveness and success was the specific style of the leader (Sadeghi \& Pihie, 2012). Patrick (2012) has also stated that a self-directed yet strict leadership behavior ultimately generates the right environment that triggers employees to participate in significant and pioneering behaviors at work, thus also shedding light on the importance of the leadership behavior and style on the work performance of employees. Employees' job satisfaction was also shown to be significantly affected by the leadership style that was implemented in the firm (Chaudhry, 2012).

The bulk of the research done on leadership styles was attributed to transformational leadership, in which leaders with this leadership style were portrayed as idealized models for their employees, and focused on widely admired behaviors that were desired by society and organizational members (Zhu et al., 2013). Transformational leadership theory has been a major topic of interest to many researchers, and the four following dimensions form the basis of the theories of transformational leadership: "idealized influence" or charisma, "motivational inspiration," “intellectual stimulation," and finally "individualized consideration” (Cavazotte et al., 2012). Transformational leaders are also known to keep a clear 
stream of communication with their employees and to always give them their undivided attention and proactive cooperation when it comes to their concerns and complaints (Zhu et al., 2013).

It is also worth mentioning a very important theory developed by Avolio \& Bass (2002), known as “The Full Range Leadership Theory," where it describes the transformational leadership style as more effective than the transactional style since it focuses more on encouraging employee innovation and high performance results (Khan et al., 2012).

Moreover, transformational Leadership differs from transactional leadership by the formation of solid relationships with employees, which in turn improves their work performance and work satisfaction, and helps in forming a bond between followers and leaders (Sadeghi \& Pihie, 2012). The positive outcomes of transformational leadership can also be shown in the resulting encouragement and inspiration that arises from implementing such a leadership style, in addition to triggering employee creativity, higher levels of work potential and effort, and finally organizational effectiveness (Sadeghi \& Pihie, 2012). On the other hand, a transactional leader fails to achieve the aforementioned desirable outcomes, since this type of leadership focuses only on negative and positive rewards according to employees’ actions and behaviors (Long et al., 2012).

Based on the aforementioned, it can be said that leaders who choose to implement a transformational leadership style will push their organization towards increased levels of effectiveness, productivity, and long-term growth and sustainability (Sadeghi \& Pihie, 2012). Moreover, the effectiveness of a transformational leadership style was also discussed in Lee et al.'s study (2013), where it was concluded that a leader should be able to successfully motivate employees and trigger them to be fully involved in their job, to ensure organizational success and effectiveness. As for Laissez-faire leadership, a relatively passive and indifferent type of behavior is present in leaders who implement such a leadership style, where such leaders fail to offer a clear path and a set of directions and expectations for their employees to follow and use as a guide; for these reasons, this type of leadership is deemed ineffective due to its extreme passiveness and indifference (Sadeghi \& Pihie, 2012). Laissez Faire leadership can also be referred to as non-transactional leadership, where it is highly attributed to the absence of any transactions, and is linked to high levels of psychological distress and role conflict for employees (Kelloway et al., 2012). 
Nowadays, leaders are arbitrated by their decisions and their sustenance of ethical treatment and fairness towards their employees. For instance, a study done by Dijke et al. (2012) has shown that leaders who trigger employees to be independent and promote their self-development and improvement will lead to procedural fairness. In addition to that, Jiang (2012) implicated that supervisors' leadership style and behavior has a direct impact on the employees’ well-being.

In light of the former and this study, the researcher strives to interpret the complex relationship between organizational justice, leadership, and power, if any. This accounts for the following section, which revolves around the definition of power and the five power sources that motivate the leaders to influence their followers.

\section{Power}

Several efforts have been invested in the study of power; and many have attempted to associate power to different variables (Brass \& Burkhardt, 1993). Pfeffer (1992) defined power as "the ability to influence behavior, to change the course of events, to overcome resistance, and to get people to do things they would not otherwise do” (Pfeffer, 1992, p. 30). According to Keltner et al. (2003, p.265), “power is an individual's relative capacity to modify others' states by providing or withholding resources or administering punishments.”

Several researchers have associated resource reliance feature with power (Keltner et al., 2003). The latter is based on the premise that competition for rare resources grants those in control of the resources the power over those who are in need of such resources.

Shackleton (1995, p.72), on the other hand, has stated that power relates to leadership and indicates that it is "impossible to talk of leadership without also discussing the question of power and influence.” This is supported by Mullins' (2002) argument that leadership involves constructing relationships that affect the behavior and attitude of others within an organization. According to Haslam (2001, p. 221), social power is "the essentially conflictual and quite ugly control of others through “domination, forced compliance and submission." Moreover, according to Patrick (2012), leaders rely on power in order to conquer the group goals in the organization.

Up until today, one of the greatest works on power remains French and Raven's (1959) Bases of Social Power Model. The framework of this model identifies five power sources that stimulate leaders to build up, leverage, and boost exercised influence over followers (French \& Raven, 1959; Handy, 1993).

The power facets include reward power, which is merely the capacity to reward and the ability to regulate valued assets of the organization (Nelson \& Quick, 2012); 
the larger the access to rewards, the stronger this facet of power is (Handy, 1993). Coercive power, which relies on control over reprimands, is principally used to secure amenableness (Lunenburg, 2012). The crux of legitimate power lies in the belief that the leader has the authority to impact and that the followers are forced to comply (Lunenburg, 2012). Referent power is dependent on the level of identification and admiration of the follower towards the leader. Finally, expert power is dependent on the established conviction that the leader holds abilities and skills that the follower requests and values (Lunenburg, 2012).

Patrick (2012) also discussed legitimate, referent, and expert power and referred to legitimate power as the outcome resulting from the employee's hierarchal position in the firm and encompasses both coercive and reward power, referent power as the process of associating one's identity with that of someone who possesses positive characteristics, and expert power as the impact of the leader's expertise and special knowledge or skills on his/her followers. It is worth mentioning that, according to a study by Varoglu (2014), a supervisor's use of referent power acted as a mediator in solving any conflicts that the subordinates have faced at work. In this paper, the researcher aims to define power in terms of the aforementioned five power bases and will attempt to relate power to leadership and organizational justice, thus acting as a robust mediator between the two factors studied. Having discussed the three types of leadership as well as the key mediator between the variables under study, the following section briefly defines the third variable.

\section{Organizational Justice (OJ)}

For the past 40 years, scholars have been engaged in the study of OJ (Greenberg, 1990). Without a doubt, a firm's most crucial asset is its human resources; therefore, treating them in a right and just manner will ultimately affect their future performance, behaviors, attitudes, and most importantly contribution to the organization (Jafari \& Bidarian, 2012). Similarly, Khan \& Rachid (2012) found that employees' overall satisfaction and commitment levels were directly affected by their perception of fairness in the organization, in particular the fairness of their leader or supervisor. Increasing employees' perception levels of organizational justice was also shown to be directly linked to organizational effectiveness, where employees tend to rely more on organizational citizenship behavior (OCB) (Lee et al., 2013). This stresses on the importance of studying organizational justice, its predecessors, as well as its successors. 
According to Gelens et al. (2013, p343), perceived organizational justice is known as “anyone’s subjective perceptions of the fairness of allocations.”

Preceding research has defined $\mathrm{OJ}$ in terms of equity theory, distribution of rewards and resources, and retort of followers towards the allocation (Adams, 1965). The core of Adam's conception is that individuals generally anticipate getting outcomes in return for their input and hard work (Cropanzano \& Randall, 1993), while the crux of Equity Theory lies in the sheer fact that workers are inclined to associate and assess the level of fairness of their distributed rewards to those of their colleagues (Greenberg, 1990).

Research gyrating around OJ has increased, shifting the research concentration from distributive justice, which is known as "employees' perceptions of how fairly they are treated by organizational authorities," to procedural justice, which is known as "organizational decision-making procedures," and interactional justice which is "the quality of interpersonal treatment received as part of these procedures" (Whitman et al., 2012). Furthermore, the scholarly study of PJ was not narrowed to the probing impartiality of procedures but also involved monitoring and observing individuals' retorts to the fairness of those certain procedures (Tyler, 1987). This type of fairness, referred to as procedural fairness or justice, is known as the extent to which employees perceive the organization's decision-making processes and its effect on the resource allocation to various organizational members as fair or just (Dijke et al., 2012). Previous research has also shown that, when procedures are applied in a consistent manner over the years, this will make them seem fairer to employees, especially when employees are involved in the decision-making process (Dijke et al., 2012). Two theoretical developments are worth mentioning: the group engagement model (Tyler \& Blader, 2003) and the self-based model of cooperation (De Cremer \& Tyler, 2005) that have indicated that, when procedures are fairly implemented in an organization, this perception of justice and fairness will in turn lead to heightened levels of employee motivation (Dijke et al., 2012). It is worth mentioning that achieving a balanced level of justice in an organization generally requires not only the fair treatment of individual employees but also that of collective business units at different hierarchal levels in the firm (Gelens et al., 2013).

Following the surge of literature that was prepared to study fairness in the allocation of resources and outcomes and its related process flows came the proliferation of interactional justice (IJ) literature that has chiefly concentrated on the prominence of the interactive associations manifested in the employment of processes and procedures (Bies \& Moag, 1986). It is worth mentioning that several scholars 
advocate distinction of interpersonal justice as a fundamental module of procedural justice and propel the separation of variables (Tyler \& Bies, 1990; Moorman, 1991). Furthermore, a study done by Whitman et al. (2012) conveyed that distributive justice was directly linked to high levels of productivity and customer satisfaction, whereas interactional justice was directly linked to the portrayal of organizational citizenship behavior and consistency.

This study has defined OJ as an individual's view towards fair allocation of resources and outcomes (distributive justice), the practice through which such distribution is executed (procedural justice) (Schminke et al., 1997), and the degree of fairness an individual exhibits in attitude and behavior while intermixing with other employees within the organization (interactional justice) (Colquitt, 2001).

Following the definitions of the variables under this study, we now look at the theoretical and significant relationship that exists between the three leadership styles and OJ, with power acting as the mediator between them.

\section{LEADERSHIP, POWER AND ORGANIZATIONAL JUSTICE}

Foregoing research has verified that a substantial relation exists between OJ and leadership, especially transformational leadership. Pillai et al. (1999) confirm the vivacious role of leadership in promoting organizational justice. They highlight the profound association between transformational leadership and procedural justice through the social exchange mechanism of transformational leadership (Pillai et al., 1999). Khan \& Rachid (2012) have also found that employees' perception of fairness in the firm (i.e. perceived organizational justice), which stems from their supervisor's leadership style, leads directly to heightened satisfaction and commitment levels in the organization.

OJ has also been directly linked to the supervisors’ implemented leadership style. For instance, aaccording to a study conducted by Gillet et al. (2013), transformational leadership leads to a high quality of work life for employees, with distributive and interactional justice acting as a mediator; hence, this study also stresses the importance of organizational justice as a key psychological mechanism that acts as a mediator between the supervisors' implemented leadership style and quality of work life for employees. Similarly, the role of the leader has been portrayed as very crucial when it comes to influencing the effectiveness of justice in an organization; this was also shown in relational fairness models, which suggest that the leader or the source of authority in an organization should represent the organization as a whole to reach the desired level of fairness in the organization (Dijke et al., 2012). 
Similarly, Niehoff and Moorman (1996) established that leader assertions and insights amplify the principles of justice throughout an organization by conveying organizational policies and related procedures to its followers. Furthermore, transformational leadership amplifies the procedural justice that induces well-being and solidarity of workforces. The chance to communicate one's own opinion and to gauge a manager's leadership skills has led the way to achieve amplified perceptions of justice and eventually fair organizations (Pillai et al., 1999).

Tyler and Caine (1981) accentuated that leadership is overcrowded by managers who oversee the connotation of fairness perceptions and whose authoritarian supremacy will most certainly be discarded by their subordinates.

Only recently has the effect of leadership style on OJ been expansively studied (Pillai et al., 1999). Lately, research has been fixated on the role of leadership styles in achieving organizational justice. It is proclaimed that justice is interconnected with leadership in relation to individual outcomes. These factors embrace trust, job satisfaction, and job performance (Pillai et al., 1999; Cropanzano et al., 2002).

Other studies have concentrated on defining the relationship between social or interactional justice and transformational leadership, investigating the central roles that they demonstrate in molding the views of justice. It is assumed that informational and interpersonal facets of interactional justice are unswervingly related to leaders' behaviors (Pillai et al., 1999; Bass, 1987; Niehoff \& Moorman, 1996; Cropanzano et al., 2002; Shamir, 1995).

Lind \& Tyler (1988) suggest that procedural justice and social power are intertwined and that individuals' ultimate concern is about social relationships with the concerned authorities enforcing and applying the procedures. Normally, subordinates develop feelings of heightened self-worth in response to the extent to which their supervisors demonstrated power aptitudes.

Bies and Moag (1986), on the other hand, focused on social power and its considerable effect on inducing perceptions of fairness, specifically interactional justice. Subordinates who are treated with respect and provided with sincere and sufficient communication will be inclined to have positive perceptions of fairness.

The literature discussed earlier clearly depicts leadership and OJ as distinct variables and power as a mediator of the former. Nevertheless, the ultimate question remains: are the dimensions of organizational justice related to leadership styles or not? What type of leadership should coexist with power to induce organizational justice? To obtain a valid response to the former, the study hypothesizes that: 
H1: All of the power bases (reward, coercive, legitimate, expert, and referent) are significantly and positively related to leadership styles.

H2: Organizational justice is significantly and positively related to each base of power.

\section{METHODOLOGY}

This study addresses the main elements of leadership, power, and OJ. Additionally, it endeavors to establish the relationship between the variables together and to link leadership styles to their corresponding dimension of OJ while keeping the variable of power as a mediator between the two variables under study.

The first part aimed to collect demographic data, including the size of the company and the respondents' age, work experience, gender, years of employment, educational level, and organizational level.

The second part applied the Multifactor Leadership Questionnaire (MLQ), developed by Bass and Avolio (1997). It comprises 21 questions, divided into 3 sections ( 3 for transactional leadership, 16 for transformational, and 2 for laissezfaire). This instrument has been proven valid and reliable, with a Cronbach's alpha of 0.86 (Muenjohn \& Armstrong, 2008). Further studies confirm the psychometrical reliability of the instrument (Avolio et al., 1997; Bass and Avolio, 1994; Bass, 1998).

The third part aimed to measure the five bases of power. For this purpose, the researcher used the Hinkin and Schreisheim's measures of the French and Raven (1959)bases of social power. This section of the questionnaire included 21 questions and inquired after power as follows: five questions related to "reward," four to "coercive," four to "legitimate," four to "expert," and four to "referent." The instrument has been proven to be valid and reliable, with a Cronbach's alpha of 0.96 (Patrick, 2012).

The fourth section in the questionnaire was comprised of questions related to OJ as the dependent construct. The researcher applied the Moorman's (1991) scale that has been proven for its validity and reliability with a Cronbach's alpha of 0.9 (AlZu'bi, 2010). This part included 20 questions: nine regarding "interactional justice," six for "procedural justice,” and five for "distributive justice.”

The adopted scale is constructed on a five-point Likert scale. The collected data was studied using the Statistical Package for Social Sciences (SPSS).

To test the hypotheses, the survey was administered between January and April 2012, during which 400 individuals working in small- to medium-sized multinational and local firms specialized in the telecommunication and electronic retail sector in 
Lebanon were surveyed. This sector was chosen due to its crucial role and contribution in the Lebanese economy. In addition, since most of the companies in this sector have high levels of professionalism and employee-oriented behavior, it made more sense to use employees working there as the respondents for this study. To ensure the efficacy of the findings, the participants were guaranteed that their identity would not be disclosed and that their anonymity will be preserved at all conditions.

\section{Descriptive Statistics \& Reliability Testing}

In the table below (Table 1), some statistical data (mean, standard deviation, variance, and Cronbach's alpha) for the 11 items in the questionnaire are mentioned: 3 items each representing one leadership style (transactional, laissez-faire, transformational), 5 items each representing one base of power (reward, coercive, legitimate, referent, and expert), and 3 items each representing one type of OJ (distributive, procedural, interactional).

Table 1 Descriptive Statistics

\begin{tabular}{lcccc}
\hline & \multicolumn{4}{c}{ Descriptive Statistics } \\
\cline { 2 - 5 } & Mean & Std. Deviation & Variance & $\begin{array}{r}\text { Cronbach's } \\
\text { Alpha }\end{array}$ \\
\hline Transactional & 4.27 & .551 & .304 & .753 \\
\hline Laissez-Faire & 1.63 & .654 & .428 & .781 \\
\hline Transformational & 4.14 & .412 & .170 & .734 \\
\hline Reward & 3.90 & .815 & .664 & .695 \\
\hline Coercive & 3.23 & 1.102 & 1.214 & .750 \\
\hline Legitimate & 4.00 & .745 & .554 & .704 \\
\hline Referent & 3.82 & .704 & 0.495 & .722 \\
\hline Expert & 4.08 & .751 & 0.563 & .688 \\
\hline Distributive & 3.30 & .984 & 0.969 & .748 \\
\hline Procedural & 3.62 & .876 & 0.767 & .690 \\
\hline Interactional & 3.84 & .721 & 0.520 & .685 \\
\hline
\end{tabular}

The composite reliability (CR) for all the above mentioned 11 items in Table I was calculated to be 0.744 , which is above 0.7 , thus indicating an acceptable statistic testing. 


\section{RESULTS \& FINDINGS}

\section{Descriptive Data}

The majority of the participants' (62\%) age ranged between 20 to 29. Around 26\% were between 30 and 39, with 60 and plus representing the lowest percentage. The percentage of females was $59 \%$ relative to $41 \%$ for males, which concludes that females provided considerably greater contributions to this study than males. Most respondents held BA/BS degrees, while the second most popular educational level was respondents who hold Master's degrees. Only $2 \%$ of the sample had Doctorate degrees. Also, more than $50 \%$ of participants had an average of 2 to 5 years of professional experience. Also, the majority of participants, $70 \%$, were operating at a non-managerial level.

\section{Regression Analysis}

Regression analysis is considered to be the most effective method to illustrate the significance of the correlation, if any, between leadership and organizational justice, provided that power is the key mediator amongst those two variables. In assessing the significance of the relationship between variables, this study applied a confidence level of $95 \%$ and a significance level of 0.05 .

\section{Leadership and Power}

This study found that power depends on the adopted Leadership Styles in an organization and formulated the results into the equations below :

\section{Regression between Reward Power and Leadership}

Equation 1: Reward Power $=1.464+0.142$ Transactional + 0.588 Transformational

The equation (1) shows a high significance $F=29.043$ and a coefficient of determination $\left(\mathrm{R}^{2}\right)=0.88$. This indicates that a positive relationship exists between reward power and transactional and transformational leadership styles.

\section{Regression between Coercive Power and Leadership}

Equation 2: Coercive Power $=0.173$ - 0.708 Transactional - 0.288 Transformational

The above mentioned equation shows a high significance $F=7.4$ and a coefficient of determination $\left(\mathrm{R}^{2}\right)=0.69$. This indicates that a negative relationship exists between coercive power and transactional and transformational leadership styles. 


\section{Regression between Legitimate Power and Leadership}

Equation 3: Legitimate Power $=1.369+0.215$ Transactional +0.381 Transformational

The above mentioned equation shows a high significance $\mathrm{F}=8.889$ and a coefficient of determination $\left(\mathrm{R}^{2}\right)=0.082$. This indicates that a positive relationship exists between legitimate power and transactional and transformational leadership styles.

\section{Regression between Expert Power and Leadership}

Equation 4: Expert Power $=0.656+0.759$ Transformational

The above mentioned equation shows a high significance $F=23.714$ and a coefficient of determination $\left(\mathrm{R}^{2}\right)=0.193$. This indicates that a positive relationship exists between the expert power and transformational leadership style.

\section{Regression between Referent Power and Leadership}

Equation 5: Referent Power $=3.101+0.296$ Laissez Faire + 0.375 Transformational

The above mentioned equation shows a high significance $F=17.568$ and a coefficient of determination $\left(\mathrm{R}^{2}\right)=0.150$. This indicates that a positive relationship exists between referent power and the transformational and laissez-faire leadership styles.

\section{Organizational Justice and Power}

\section{Regression between Distributive Justice and Power}

Equation 1: Distributive Justice $=1.916+0.211$ Reward -0.126 Coercive + 0.39Legitmiate

As per the above equation, there is a significant relation between power (reward, coercive, and legitimate power) and distributive justice. The coefficient of determination $\left(\mathrm{R}^{2}\right)$ is 0.092 , which surmises that $9.2 \%$ of deviation in distributive justice is explicated by the variation in power variables. The findings also show an Fvalue of 6.011. Hence, distributive justice is positively related to reward and legitimate power, while it is negatively related to coercive power.

\section{Regression between Procedural Justice and Power}

Equation 2: Procedural Justice $=0.149+0.81$ Reward - 0.78Coercive + 0.223Legitmiate +0.343 Expert 
A significant relationship exists between power (reward, coercive, legitimate, and expert power) and procedural justice. The coefficient of determination $\left(\mathrm{R}^{2}\right)$ is 0.331 , which concludes that $33.1 \%$ of the variation in procedural justice is explicated by the variation in power variables. Also, findings show an F-value of 29.252. Hence, it is evident that procedural justice is positively related to reward, legitimate, and expert power and negatively related to coercive power.

\section{Regression between Interactional Justice and Power}

Equation 3: Interactional Justice $=0.471+0.347$ Expert +0.161 Referent

A significant relation exists between interactional justice and power (expert and referent power). The coefficient of determination $\left(\mathrm{R}^{2}\right)$ is 0.501 , which indicates that $50.01 \%$ of variation in interactional justice is explicated by the variation in power variables. The findings also show an F-value of 59.503. Hence, one can infer that interactional justice is significantly and positively related to expert and referent power.

\section{Path Analysis}

The regression analysis indicates that, to elucidate the relationship between the variables under study and to highlight the indirect link that associates leadership and OJ through the power bases model, path analysis was executed on the data. The below figure depicts the path analysis results along with path coefficients aligning the arrows connecting the various variables. It outlines the degree to which the variables directly and indirectly affect OJ.

As indicated in Figure 1, in order to attain distributive justice, a leader can either adopt transactional or transformational leadership provided that reward and legitimate powers are applied in tune with the adopted leadership style.

In the course of achieving procedural justice, a leader must employ either transactional or transformational leadership and apply reward, legitimate, and expert power. It is interesting to note that procedural justice will be enhanced only when a transformational leader uses legitimate and expert power in an organization.

On the other hand, the realization of interactional justice rests on the adoption of either transformational or laissez-faire leadership and effectively through referent and expert power. It is important to mention that, according to the above figure, only transformational leadership can concretely pave the way for the realization of the three dimensions of OJ: distributive, procedural, and interactional justice. 


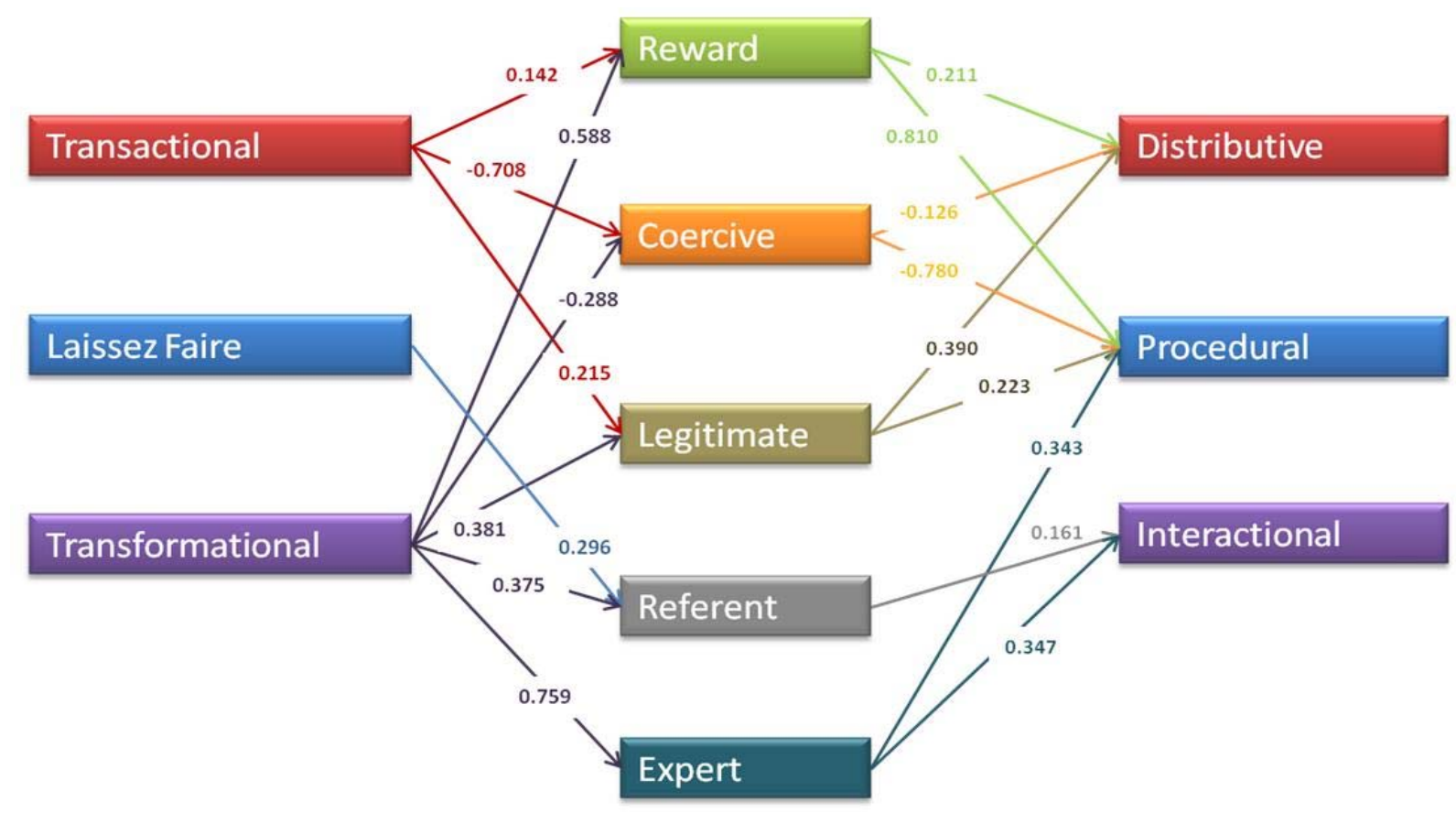

Figure 1 Path Analysis Results including Path Coefficients

\section{DISCUSSION}

Various studies have related OJ to critical organizational outcomes including organizational commitment, job performance, job satisfaction, and organizational citizenship (Deng, 2012; Colquitt et al., 2002; Mayer et al., 2007; Emery \& Barker, 2007; Chen, 2005). Lately, the literature has concentrated on defining the nature of the association between OJ and leadership styles. This study sustains the theoretical relationships advocated by other scholars (Tatum et al., 2003) by examining the relationship between $\mathrm{OJ}$ and leadership styles while considering the different bases of power as the mediator between the two variables.

In order to advance theory development in the OJ literature, hypotheses were constructed and tested during the course of this research. Transactional leadership critically exhibited a marginally acceptable degree of organizational justice in terms of distributive and procedural justice while maintaining reward, coercive, and legitimate powers as mediators, Transformational leadership demonstrated substantially higher ratings of organizational justice in its three dimensions, provided that 5 bases of power coexisted as liaisons among the transformational leadership and the dimensions of OJ. Results also show that a significant relationship exists between transformational and laissez-faire leadership styles, with referent power mediating the relationship. 
These findings can be linked to previous research done by Yahaya et al. (2011), which identifies the relationship between power style, personality dimension, and leadership style. The research findings showed that reward, coercive, and legitimate powers are predictors for transactional leadership; the more of these power bases the leader exercised, the more transactional the follower perceived him or her (Yahaya et al., 2011), thus limiting transactional leadership to only the aforementioned three power variables.

It is worth mentioning that, according to the researcher's knowledge, no studies have been conducted to clarify the relationship between laissez-faire leadership and referent power, due to the unpopularity of this type of leadership.

Tatum et al. (2003) proposed that a solid association exists between the facets of OJ and leadership styles. They confirm that transactional leaders disburse most of their energies and efforts on a provisional reward mechanism through which they remunerate high performing individuals with valued rewards. A transactional leader must meticulously monitor individuals' performance and unravel the elusive hints in order to evaluate the deservedness of individuals towards the distribution of rewards. This complies with the findings of this study, which exhibit a significant relation between transactional leadership to sustain distributive and procedural justice, provided reward, coercive, and legitimate powers.

Based on the interpretations of the path analysis, the concrete relationship between transformational leadership and the five power bases and the latter's considerable effect on the realization of organizational justice in its three dimensions confirms the suggestion by Hogg and Knippenberg (2003) of the profound relationship between social power and leadership. It also complies with the findings by Brockner (2006), who relate social power to procedural justice.

Moreover, scholars corroborate that, when leaders exhibit holistic apprehension of organizational objectives and goals, they are demonstrating transformational leadership. Hence, transformational leaders are proficient at addressing conceivable hurdles that may come across in the future. Most scholars highlight that there exists a strong relationship between OJ dimensions and transformational leadership. The crux of interactional justice resides in interpersonal sympathy and societal accountability (Folger \& Cropanzano, 1998), and interactive sympathy is in line with the framework of employee contemplation that is manifested in transformational leadership (Chan, 2000). Moreover, it is presumed that transformational leaders are graded higher in the context of social components of fairness by their subordinates than leaders employing a transactional style (Tatum et al., 2002). 
Expectedly, laissez-faire leaders are most likely to fail to construe individual deservedness and lead to unfair allocation of rewards. This nearly complies with the findings of this study that conclude the existence of a significantly positive relation between laissez-faire and interactional leadership, provided that referent power coexists.

In summary, none of the leadership styles under study win out over the other. Whether it is transformational, transactional or, the least of all, a laissez-faire leadership style, they all depend on the power bases that coexist with them and the extent to which their cohabitation influences the attainment of $\mathrm{OJ}$ in an organization.

\section{CONCLUSION IMPLICATIONS \& LIMITATIONS}

\section{Conclusion and Implications}

Managers, in the course of acting upon their title roles, are prone to taking cognitively biased decisions. When a leader prominently fails to foretell the destructive effects executed on his/her followers due to their biased judgments, the leader then has not conveyed the fundamental modules of OJ. Biased leaders who are vulnerable to cognitive dissention are inclined to make decisions and judgments that are viewed as unethical and unjust by their followers. This stimulates considerably low levels of OJ, raises employee resistance and weakens employees' commitment towards the organization; thus, leaders must always be abreast of the treasured perseverance of OJ and its implications (Tatum et al., 2002; Adams, 1965; Leventhal, 1980; Colquitt et al., 2002).

This study has reinforced the suggested theoretical hypotheses and outlaid interpretations and conclusions that contribute to the literature by intensifying the understanding of $\mathrm{OJ}$ in relation to leadership and power and the relevant implications of OJ's three facets towards the success and prosperity of an organization. The success of an organization hinges on the appropriate type of leadership style accompanied by the application of power bases that best contribute to the achievement of an organizational justice that secures fair treatment to its employees.

\section{Limitations and Direction for Future Research}

The primary limitation of this study is the comparatively small sample size. A larger sample size would most definitely provide relatively more decisive findings and conclusive interpretations. Hence, it is advisable that future research replicate the study using a larger sample size. Also, it would be beneficial to conduct the research in other prominent sectors in Lebanon, where the effect of leadership styles on 
different facets of organizational justice and the role of power as a mediator between the two variables can be studied across different Lebanese sectors, and a useful comparison can be made accordingly.

It is worth mentioning that this study was restricted to quantitative measures and flouted valuable findings that could have been attained through the use of qualitative analysis of the OJ, leadership, and power constructs. Hence, to further support the results of this research and improve upon it, it is recommended that future studies employ qualitative measures that may include focus groups and interviews.

As discussed earlier, the percentage of female participation in this study was 59\% as opposed to $41 \%$ for males, meaning that the contribution of females to the results of the research was considerably greater than that of males. Based on the fact that the sample was relatively unbalanced in terms of gender, one may come to the conclusion that the gender difference may have influenced the current findings. Although this study doesn't identify gender as a distinct factor and ultimately expropriates any presumptuous implications it may have had either on organizational justice, leadership, or power, this however, opens up new horizons for further research that studies the effect of gender, if any, on the variables under study.

Finally, further research could be conducted to study the relationship between the hierarchical position of the individual (more specifically managerial/non-managerial) and his/her response regarding the understanding of OJ in relation to leadership and power.

\section{REFERENCES}

Adams, J. S. (1965). Inequity in social exchange. In L. Berkowitz (Ed.), Advances in experimental social psychology, New York: Academic Press, 2,267-299. http://dx.doi.org/10.1016/S0065-2601(08)60108-2

Al-Zu'bi, H. A. (2010). A study of relationship between organizational justice and job satisfaction. International Journal of Business and Management, 5(12), 102. http://dx.doi.org/10.5539/ijbm.v5n12p102

Anderson, D., \& Ackerman-A., L. (2011). Conscious change leadership: Achieving breakthrough results. Leader to Leader, 62, 51-59. http://dx.doi.org/10.1002/ltl.493

Avolio, B. J., Bass, B. M. and Jung, D. I. (1997). Replicated Confirmatory Factor Analyses of the Multifactor Leadership Questionnaire. Center f or Leadership Studies, Binghamton University, Binghamton, NY. 
Avolio, B. J., Bass, B. M., \& Dong, L. J. (1999). Re-examining the components of transformational and transactional leadership using multifactor leadership questionnaire. Journal of Occupational and Organizational Psychology, 72(4), 441-462. http://dx.doi.org/10.1348/096317999166789

Avolio, B. J., \& Bass, B. M. (2002). Developing potential across a full range of leadership: Cases on transactional and transformational leadership. Mahwah, NJ: Lawrence Erlbaum.

Bass, B. M. (1985). Leadership and Performance beyond Expectations. Free Press, New York, NY.

Bass, B.M., Avolio, B.J., \& Goodheim, L. (1987). "Biography and the Assessment of Transformational Leadership at the World-Class Level”. Journal of Management, Vol. 13, no. 1 7-19.

Bass, B. M. (1998). Transformational Leadership: Industry, Military, and Educational Impact. Lawrence Erlbaum Associates, Mahwah, NJ.

Bass, B. M., \& Avolio, B. J. (1994). Improving organizational effectiveness through transformational Leadership. Thousand Oaks, CA: Sage.

Bass, B. M., \& Avolio, B. J. (1997). Full range of leadership: Manual for the Multifactor Leadership Questionnaire. Redwood City, CA: Mind Garden.

Bies, R. J., \& Moag, J. F. (1986). Interactional justice: Communication criteria of fairness. In R. J. Lewicki, B. H. Sheppard, \& M. H. Bazerman (Eds.), Research on negotiations in organizations, Greenwich, CT: JAI Press, (1), 43-55.

Brass, D. J., \& Burkhardt, M. E. (1993). Potential power and power use: An investigation of structure and behavior. Academy of Management Journal, 36(3), 441-470. http://dx.doi.org/10.2307/256588

Brockner J (2006). Why it's so hard to be fair. Harvard Business Review, 84(3), 122129.

Cavazotte, F., Moreno, V., \& Hickmann, M. (2012). Effects of leader intelligence, personality and emotional intelligence on transformational leadership and managerial performance. The Leadership Quarterly, 23(3), 443-455. http://dx.doi.org/10.1016/j.leaqua.2011.10.003

Chan, M. (2000). Organizational justice theories and landmark cases. International Journal of Organizational Analysis, 8(1), 68-88. http://dx.doi.org/10.1108/eb028911

Chaudhry, K.R.A.G. (2012),"Leadership - style, satisfaction and commitment". Engineering, Construction and Architectural Management, 19(1), 61 - 85. 
Chen, L.-T. (2005). Exploring the relationship among transformational and transactional leadership behavior, job satisfaction, organizational commitment, and turnover on the IT Department of Research and Development in Shanghai, China. Retrieved from Dissertations \& Theses: Full Text database (AAT 3169070).

Choudhry, N., Philip, P.J., \& Kumar, R. (2011). Impact of Organizational Justice on Organizational Effectiveness. Industrial Engineering Letters, 1, No.3.

Colquitt, J. A. (2001). On the dimensionality of organizational justice: A construct validation measure. Journal of Applied Psychology, 86(3), 386. http://dx.doi.org/10.1037/0021-9010.86.3.386

Colquitt, J. A., Noe, R. A. \& Jackson, C. L. (2002). Justice in teams: Antecedents and consequences of procedural justice climate. Personnel Psychology, 55(1), 83-109. http://dx.doi.org/10.1111/j.1744-6570.2002.tb00104.x

Cropanzano, R., \& Randall, M. L. (1993), Injustice and work behaviour: A historical review. In R. Cropanzano (Ed.), Justice in the workplace: Approaching fairness in human resource management Hillsdale, NJ: Erlbaum, 79-103.

Cropanzano, R., Prehar, C. A., \& Chen, P. Y. (2002). Using social exchange theory to distinguish procedural from interactional justice. Group \& Organization Management, 27(3), 324 -351. http://dx.doi.org/10.1177/1059601102027003002

De Cremer, D., \& Tyler, T. R. (2005). Managing group behavior: The interplay between procedural justice, sense of self, and cooperation. In M. P. Zanna (Ed.). Advances in experimental social psychology, 37, 151-218. San Diego, CA, US: Elsevier Academic Press. http://dx.doi.org/10.1016/S0065-2601(05)37003-1

Deng, G. (2012). An Empirical Study of Organizational Justice, Organizational Citizenship Behavior and Service Fairness. In Technology for Education and Learning, 27-34. Springer Berlin Heidelberg.

Dijke, M.V., Cremer, D.D., Mayer, D.M., \& Quaquebeke, N.V. (2012). When does procedural fairness promote organizational citizenship behavior? Integrating empowering leadership types in relational justice models. Organizational Behavior and Human Decision Processes, 117(2)235-248. http://dx.doi.org/10.1016/j.obhdp.2011.10.006

Eberlin, R. J. (2005). The relationship among leadership style, decision making, and organizational justice. Retrieved from Dissertations \& Theses: Full Text database (AAT 3184407).

Emery, C. R., \& Barker, K. J. (2007). The effect of transactional leadership styles on the organizational commitment and job satisfaction of customer contact 
personnel. Journal of Organizational Culture, Communication and Conflict, 11(1), 77-90.

Folger, R., \& Cropanzano, R. (1998). Organizational justice and human resource management. Thousand Oaks, CA: Sage.

French, J., \& Raven, B. H. (1959). The bases of social power. In D. Cartwtight (Ed.), Studies in social power. Ann Arbor, University of Michigan, Institute for Social Research, 150-167.

Gelens, J., Dries, N., Hofmans, J., Pepermans, R. (2013). The role of perceived organizational justice in shaping the outcomes of talent management: A research agenda. Human Resource Management Review, 23(4),341-353. http://10.1016/j.hrmr.2013.05.005

Gillet, N., Fouquereau, E., Bonnaud-Antignac, A., Mokounkolo, R., Colombat, P. (2013).The mediating role of organizational justice in the relationship between transformational leadership and nurses' quality of work life: A cross-sectional questionnaire survey. International Journal of Nursing Studies, 50(10), 13591367.

Greenberg, J. (1990). Employee theft as a reaction to underpayment Inequity: The hidden cost of pay cuts. Journal of Applied Psychology, 75(5), 561-568. http://dx.doi.org/10.1037/0021-9010.75.5.561

Handy, C. (1993), Understanding Organisations, (4 ${ }^{\text {th }}$ ed.), Penguin, Harmondsworth.

Haslam, S. A. (2001). Psychology in organizations: The social identity approach. London: Sage.

Hogg, M. \& Knippenberg, D.Van (2003). Leadership and Power: Identity Processes in Groups and Organizations. London: Sage. Identity, leadership, and power, 123137.

Jafari, P., Bidarian, S. (2012). The relationship between organizational justice and organizational citizenship behavior. Procedia-Social and Behavioral Sciences, 47, 1815 - 1820. http://dx.doi.org/10.1016/j.sbspro.2012.06.905

Jiang, H. (2012). A model of work-life conflict and quality of employee-organization relationships (EORs): Transformational leadership, procedural justice, and family-supportive workplace initiatives. Public Relations Review,38(2), 231-245. http://dx.doi.org/10.1016/j.pubrev.2011.11.007

Khan, M.J., Aslam, N., Riaz, M.N. (2012). Leadership Styles as Predictors of Innovative Work Behavior. Journal of Social and Clinical Psychology, 9(2), 1722. 
Khan, S.K., Rachid, M.Z.A. (2012). The Mediating Effect of Organizational Commitment in the Organizational Culture, Leadership and Organizational Justice Relationship with Organizational Citizenship Behavior: A Study of Academicians in Private Higher Learning Institutions in Malaysia. International Journal of Business and Social Science Vol. 3 No. 8.

Kelloway, E.K.,Turner,N., Barling, J., \& Loughlin, C.(2012) Transformational leadership and employee psychological well-being: The mediating role of employee trust in leadership, Work \& Stress: An International Journal of Work, Health \& Organisations, 26(1), 39-55, http://dx.doi.org/10.1080/02678373.2012.660774

Keltner, D., Gruenfeld, D.H. \& Anderson, C. (2003). Power, approach, and inhibition. Psychological Review, 110(2), 265-84. http://dx.doi.org/10.1037/0033295X.110.2.265

Lee, U.H., Kim, H,K., \& Kim, Y.H. (2013). Determinants of Organizational Citizenship Behavior and Its Outcomes. Global Business and Management Research: An International Journal, 5(1), 54-65.

Leventhal, G.S. (1980). "What Should be Done with Equity Theory, New Approaches to the Study of Fairness in Social Relationships”. Social Exchange, Advances in theory and research, 27-55.

Lind, E. A., \& Tyler, T. R. (1988). The social psychology of procedural justice. New York: Plenum.

Long, C.S. \& Thean, L.Y., (2011). Relationship Between Leadership Style, Job Satisfaction and Employees’ Turnover Intention: A Literature Review. Research Journal of Business Management, 5, 91-100.

Long, C.H., Thean, L.Y., Ismail, W.K.W., \& Jusoh, A. (2012). Leadership Styles and Employees' Turnover Intention: Exploratory Study of Academic Staff in a Malaysian College. World Applied Sciences Journal, 19(4), 575-581.

Lunenburg, F.C. (2012). Power and Leadership: An Influence Process. International Journal of Management, Business, and Administration, 15(1), 1-9.

Mayer, D., Nishii, L., Schneider, B., \& Goldstein, H. (2007). The precursors and products of justice climates: Group leader antecedents and employee attitudinal consequences. Personnel Psychology, 60(4), 929-963.

Muenjohn, N., Armstrong, A. (2008). Evaluating the Structural Validity of the Multifactor Leadership Questionnaire (MLQ), Capturing the Leadership Factors of Transformational-Transactional Leadership. Contemporary Management 
Research.

http://dx.doi.org/10.1111/j.1744-6570.2007.00096.x

Moon, H., Kamdar, D., Mayer, D. M., \& Takeuchi, R. (2008). Me or we: The role of personality and justice as other-centered antecedents to taking charge within organizations. Journal of Applied Psychology, 93(1), 8494. http://dx.doi.org/10.1037/0021-9010.93.1.84

Moorman, R. H. (1991). Relationship between organizational justice and organizational citizenship behaviors: Do fairness perceptions influence employee citizenship. Journal of Applied Psychology, 76(6), 845-855. http://dx.doi.org/10.1037/0021-9010.76.6.845

Mullins, L.J. (2002), Management and Organisational Behaviour, (6 ${ }^{\text {th }}$ Ed), Prentice Hall, London.

Nelson, D.L. \& Quick, J.C. (2012). Understanding Organizational Behavior (4 ${ }^{\text {th }}$ Ed). Mason, $\mathrm{OH}$ :South-Western/, Cengage learning.

Niehoff, B. P., \& Moorman, R. H. (1996). Exploring the relationships between top management behaviors and employee perceptions of fairness. International Journal of Public Administration, 19(6), $941 \quad$-962. http://dx.doi.org/10.1080/01900699608525126

Pfeffer, J., (1992), Managing with Power: Politics and Influence in Organizations, Harvard Business School Press, Boston, MA.

Pillai, R., Scandura, T. A., \& Williams, E. A. (1999). Leadership and organizational justice: Similarities and differences across cultures. Journal of International Business Studies, 30(4), 763-779. http://www.jstor.org/stable/155344

Sadeghi, A., Pihie, Z.A.L. (2012). Transformational Leadership and Its Predictive Effects on Leadership Effectiveness. International Journal of Business and Social Science. 3(7), 186-197.

Samad, S. (2012). The Influence of Innovation and Transformational Leadership on Organizational Performance. Procedia - Social and Behavioral Sciences 57,486 493. http://dx.doi.org/10.1016/j.sbspro.2012.09.1215

Schminke, M., Ambrose, M. L. \& Noel, T. W. (1997). The effect of ethical frameworks on perceptions of organizational justice. Academy of Management Journal, 40(5), 1190-1207.

Shackleton, V. (1995), Business Leadership, Routledge, London.

Shamir, B. (1995). Social distance and charisma: Theoretical notes and an exploratory study. Leadership Quarterly. 40(5),19-47. http://dx.doi.org/10.2307/256932 
Tatum, B. C., Bradberry, T., Eberlin, R., \& Kottraba, C. (2002). Organizational justice and performance as measured by a 360-degree feedback instrument. Poster presented at the 14th Annual Convention of the American Psychological Society, New Orleans, LA, June.

Tatum, B. C., Eberlin, R., Kottraba, C., \& Braderry, T. (2003). Leadership, decision making, and organizational justice. Management Decision, 41(10), 1006-1016. http://dx.doi.org/10.1108/00251740310509535

Tyler T.R. (1987). Conditions leading to Value Expressive Effects in Judgementsof Procedural Justice: A Test of Four Models. Journal of Personality and Social Psychology, 52(2), 333-344. http://dx.doi.org/10.1037/0022-3514.52.2.333

Tyler, T. R., \& Bies, R. J. (1990). Beyond formal procedures: The interpersonal context of procedural justice. In J. S. Carroll (Ed.), Applied social psychology and organizational settings. Hillsdale. NJ: Erlbaum, 77-98.

Tyler, T. R., \& Blader, S. L. (2003). The Group Engagement Model: Procedural justice, social identity, and cooperative behavior. Personality and Social Psychology Review, 7(4), 349-361. http://dx.doi.org/10.1207/S15327957PSPR0704_07

Tyler, T., \& Caine, A. (1981). The role of distributive justice and procedural fairness in the endorsement of formal leaders. Journal of Personality and Social Psychology, 41, Retrieved April 24, 2008, from PsychARTICLES database, 643 $-655$.

Varoglu, M.K.K.C.E.K. (2014). Bases of power and conflict intervention strategy: a study on Turkish managers. International Journal of Conflict Management, 25(1), 38 - 60. http://dx.doi.org/10.1108/IJCMA-05-2012-0041

Whitman, D.S., Caleo, S., Carpenter, N.C., Horner, M.T., \& Bernerth, J.B. (2012). Fairness at the Collective Level: A Meta-Analytic Examination of the Consequences and Boundary Conditions of Organizational Justice Climate. Journal of Applied Psychology, 97(4), 776791. http://dx.doi.org/10.1037/a0028021

Yahaya, N., Mohammad Taib, M.A.B., Ismail, J., Shariff, Z, Yahaya ,A., Boon ,Y\& Hashim,S.(2011). Relationship between leadership personality types and source of power and leadership styles among managers. African Journal of Business Management, 5(22).

Yuan, C.K., \& Lee, C.Y. (2011). Exploration of a construct model linking leadership types, organization culture, employees performance and leadership performance. 
Procedia - Social and Behavioral Sciences, 25, 123-136. http://dx.doi.org/10.1016/j.sbspro.2011.10.534

Zhu, W., Newman, A., Miao, Q., \& Hooke, A. (2013). Revisiting the mediating role of trust in transformational leadership effects: Do different types of trust make a difference?. The Leadership Quarterly, 24 (1), 94-105. http://dx.doi.org/10.1016/j.leaqua.2012.08.004 
